\title{
Importance of follow-up after delivery in women who experience hypertensive disorders during pregnancy
}

\author{
Hiromichi Suzuki \\ Hypertension Research (2015) 38, 709-710; doi:10.1038/hr.2015.83; published online 23 July 2015
}

$\mathrm{H}$ ypertensive pregnancy disorders, which include preeclampsia and gestational hypertension, are known to be associated with various adverse health outcomes for mothers and their children. Women with hypertensive pregnancy disorders have a high risk of cardiovascular disease later in life. ${ }^{1}$ Their offspring have also been reported to be hypertensive at a younger age. ${ }^{2}$

Recently, the Japanese Hypertension Guidelines for Self-monitoring of Blood Pressure at home (HBPM) $)^{3}$ were published. The recommendations in these guidelines are essentially identical to those of other guidelines, such as those of the European Society of Hypertension ${ }^{4}$ and the American Heart Association. ${ }^{5}$ There is a positive relationship between HBPM and accurate cardiovascular disease prognosis, which is the main reason why HBPM is recommended for patients with hypertension. There is much evidence demonstrating that HBPM is more predictive of hypertensive target-organ damage and provides a better prognosis of cardiovascular disease than blood pressure levels measured at a clinic, and that HBPM is nearly as accurate as ambulatory blood pressure monitoring. In pregnant women, several reports ${ }^{6-8}$ have demonstrated that for detecting early changes in blood pressure during pregnancy, HBPM is superior to measuring blood pressure in a clinic. However, no studies have evaluated blood pressure in mothers with hypertensive pregnancy disorders and their offspring by using HBPM.

In this issue of the journal, Hosaka et al. ${ }^{9}$ present the blood pressure levels for a mother

$\mathrm{H}$ Suzuki is at Director of Musashino Tokusyukai Hospital, Department of Nephrology, Saitama Medical University, 38 Morohongo, Moroyama Machi, Saitama, Japan

E-mail: iromichi@saitama-med.ac.jp and her offspring 7 years after delivery and compare the blood pressure levels between HBPM and clinical measurements. The main conclusion from this study is that hypertensive pregnancy disorders are closely correlated to a mother's elevated blood pressure later in life but have no influence on her offspring at 7 years of age.

Until now, a variety of findings on gestational hypertension and preeclampsia have been reported as hypertensive pregnancy disorders, although these two conditions are quite distinct. Preeclampsia is defined as newly elevated blood pressure $(>140 / 90 \mathrm{~mm} \mathrm{Hg}$ ) and proteinuria ( $0.3 \mathrm{~g}$ per $24 \mathrm{~h}$ ) after 20 weeks of gestation. Gestational hypertension is defined as newly elevated blood pressure after 20 weeks of gestation but without proteinuria. Therefore, it has been suggested that the mechanisms underlying the association of preeclampsia or gestational hypertension with the offspring's blood pressure may differ between these disorders. Blood pressure elevation in the children of women with preeclampsia is mediated by low birth weight and preterm delivery, although the association between preeclampsia and blood pressure elevation in the offspring does not simply reflect an association between preeclampsia and fetal growth or preterm birth. ${ }^{10,11}$ Moreover, some authors ${ }^{10,12}$ have reported that after adjusting for differences in offspring birthweight and gestational age, the differences in blood pressure are still observed. In contrast, gestational hypertension has not been associated with these factors. In the article by Hosaka et al. ${ }^{9}$, a large proportion of the women with hypertensive pregnancy disorders had gestational hypertension. There were no significant differences in birth weight and gestational age between women with gestational hypertension and non-hypertensive pregnancy disorders. According to a metaanalysis by Ferreira et $a l^{2}$ the differences in blood pressure between the offspring of women with preeclamptic and normotensive pregnancies were $2.3 \mathrm{~mm} \mathrm{Hg}$ for systolic blood pressure ( $95 \%$ confidential interval (CI): 1.6-3.0) and $1.7 \mathrm{~mm} \mathrm{Hg}$ for diastolic blood pressure (95\% CI: 0.9-2.4). However, the pooled mean difference in systolic blood pressures was not affected by heterogeneity. Hetereogeneity may have affected the mean difference in diastolic blood pressure. In addition, women with hypertensive pregnancy disorders demonstrated high blood pressure at an average of 10 years after pregnancy. For example, Øglaend et al. ${ }^{13}$ demonstrated that women with a past history of preeclampsia had elevated blood pressures 11-12 years after pregnancy. They also reported that the differences in blood pressure between the offspring of women with preeclampsia and normotensive pregnancies were exacerbated by their mothers' higher blood pressures. From Øglaend et al.'s data, there is a possibility that elevated blood pressure in the offspring of women with preeclampsia reflects merely a familial aggregation. Compared with preeclampsia, gestational hypertension is more related to essential hypertension. In this study, the proportion of hypertension-positive family histories was significantly higher in women with gestational hypertension than in those with non-gestational hypertension (39 vs 68\%). This also relates to elevated blood pressure in women with a past history of gestational hypertension, although there was very little difference in systolic blood pressure between the women who experienced gestational hypertension and those who did not. Östlund et al. ${ }^{14}$ reported an interesting observation 
that there was normalization of endothelial function 11 years after delivery, indicating that cardiovascular risk factors might be present before pregnancy. Combining these findings with previously reported results, whether preeclampsia causes blood pressure elevation in both the mother and her offspring remains controversial. Therefore, further exploration of the association between hypertensive pregnancy disorders and offspring blood pressure is needed.

In summary, the work of Hosaka et al. represents a good example of the use of HBPM for the early detection of blood pressure elevation later in life in women with hypertensive pregnancy disorders and their offspring after delivery.

\section{CONFLICT OF INTEREST}

The author declares no conflict of interest.

1 McDonald SD, Malinowski A, Zhou Q, Yusuf S Devereaux PJ. Cardiovascular sequelae of preeclampsia/eclampsia: a systematic review and meta-analyses. Am Heart J 2008; 156: 918-930.

2 Ferreira I, Peeters LL, Stehouwer CD. Preeclampsia and increased blood pressure in the offspring: meta-analysis and critical review of the evidence. J Hypertens 2009; 27: 1955-1959.

3 Imai $Y$, Kario $K$, Shimada $K$, Kawano $Y$, Hasebe $N$, Matsuura H, Tsuchihashi T, Ohkubo T, Kuwajima I, Miyakawa MJapanese Society of Hypertension Committee for Guidelines for Self-monitoring of Blood Pressure at Home. The Japanese Society of Hypertension guidelines for self-monitoring of blood pressure at home (second edition). Hypertens Res 2012; 35: 777-795.

4 Parati G, Stergiou GS, Asmar R, Bilo G, de Leeuw P, Imai $Y$, Kario K, Lurbe E, Manolis A, Mengden T, O'Brien E, Ohkubo T, Padfield P, Palatini P, Pickering $T$, Redon J, Revera M, Ruilope LM, Shennan A, Staessen JA, Tisler A, Waeber B, Zanchetti A, Mancia GESH Working Group on Blood Pressure Monitoring. European Society of Hypertension practice guidelines for home blood pressure monitoring. J Hum Hypertens 2010; 24: 779-785.

5 Pickering TG, Miller NH, Ogedegbe G, Krakoff LR, Artinian NT, Goff D. Call to action on use and reimbursement for home blood pressure monitoring: a joint scientific statement from the American Heart Association, American Society Of Hypertension, and Preventive Cardiovascular Nurses Association. Hypertension 2008; 52: 10-29.

6 Ishikuro M, Obara T, Metoki H, Ohkubo T, Yamamoto M, Akutsu K, Sakurai K, Iwama N, Katagiri M, Yagihashi K, Yaegashi N, Mori S, Suzuki M, Kuriyama S, Imai Y. Blood pressure measured in the clinic and at home during pregnancy among nulliparous and multiparous women: the BOSHI study. Am J Hypertens 2013; 26: 141-148.

7 Metoki H, Ohkubo T, Obara T, Akutsu K, Yamamoto M, Ishikuro M, Sakurai $\mathrm{K}$, Iwama $\mathrm{N}$, Katagiri $M$ Sugawara J, Hirose T, Sato M, Kikuya M, Yagihashi K, Matsubara Y, Yaegashi N, Mori S, Suzuki M, Imai YBOSHI Study Group. Daily serial hemodynamic data during pregnancy and seasonal variation the BOSHI study. Clin Exp Hypertens 2012; 34 290-296.

8 Waugh J, Habiba MA, Bosio P, Boyce T, Shennan A, Halligan AW. Patient initiated home blood pressure recordings are accurate in hypertensive pregnant women. Hypertens Pregnancy 2003; 22: 93-97.

9 Hosaka M, Asayama K, Staessen JA, Tatsuta N, Satoh M, Kikuya M, Ohkubo T, Satoh H, Imai Y, Nakai K. Relationship between maternal gestational hypertension and home blood pressure in 7-year-old childeren and their mothers: Tohoku Study of Child Development. Hypertens Res 2015; 38: 776-782.

10 Taittonen L, Nuutinen M, Turtinen J, Uhari M. Prenatal and postnatal factors in predicting later blood pressure among children: cardiovascular risk in young Finns. Pediatr Res 1996; 40: 627-632.

11 Walker BR, McConnachie A, Noon JP, Webb DJ, Watt GC. Contribution of parental blood pressures to association between low birth weight and adult high blood pressure: cross sectional study. BMJ 1998; 316 834-837.

12 Vatten LJ, Romundstad PR, Holmen TL, Hsieh CC, Trichopoulos D, Stuver SO. Intrauterine exposure to preeclampsia and adolescent blood pressure, body size, and age at menarche in female offspring. Obstet Gynecol 2003; 101: 529-533.

13 Øglaend B, Forman MR, Romundstad PR, Nilsen ST, Vatten LJ. Blood pressure in early adolescence in the offspring of preeclamptic and normotensive pregnancies. J Hypertens 2009; 27: 2051-2054.

14 Östlund E, Al-Nashi M, Hamad RR, Larsson A, Eriksson $M$, Bremme $K$, Kahan T. Normalized endothelial function but sustained cardiovascular risk profile 11 years following a pregnancy complicated by preeclampsia. Hypertens Res 2013; 36 1081-1087. 